\title{
“MODO DEL DECIR" EN LAS CRÓNICAS MISIONERAS. LAS HISTORIAS DE MOTOLINÍA Y MENDIETA
}

\author{
"WAYS OF TELLING" IN MISSIONARY CHRONICLES. \\ THE HISTORIAS OF MOTOLINÍA AND MENDIETA
}

\author{
María Inés Aldao \\ Doctora en Letras \\ Universidad Nacional de La Plata / Universidad de Buenos Aires \\ CONICET \\ Argentina \\ inesaldao@hotmail.com
}

\begin{abstract}
Resumen: Las crónicas Historia de los indios de la Nueva España e Historia eclesiástica indiana de los frailes misioneros Toribio de Benavente Motolinía y Gerónimo de Mendieta, respectivamente, son textos que se distinguen del resto del corpus franciscano en una serie de características que conforman un particular "modo del decir" la evangelización novohispana y la función del yo que enuncia. En este artículo analizo las crónicas desde una perspectiva literaria y describo los recursos y el posicionamiento enunciativo que hacen de estas Historias textos únicos de la cronística colonial hispanoamericana.
\end{abstract}

Palabras clave: Crónicas misioneras; Toribio de Benavente Motolinía; Gerónimo de Mendieta; "Modos del decir"; evangelización novohispana.

Abstract: Historia de los indios de la Nueva España and Historia eclesiástica indiana written by the missionary friars Toribio de Benavente Motolinía and Gerónimo de Mendieta are chronicles which differ from the rest of the Franciscan corpus in a series of characteristics which conform a specific "way of telling" the novohispanic evangelization and the function of the enunciating self. In this article I analyse these chronicles from a literary perspective and I describe the literary resources and the enunciating position that make these texts unique among the colonial Spanish American chronicle.

Keywords: Missionary chronicles; Toribio de Benavente Motolinía; Gerónimo de Mendieta; "ways of telling"; novohispanic evangelization.

Recibido: 03/08/2020. Aceptado: 01/06/2021. 


\section{Introducción}

n 1524 los Primeros Doce franciscanos liderados por fray Martín de Valencia llegaron a México. De inmediato comenzaron una ardua labor evangelizadora que implicó el recorrido a pie y descalzos por el territorio aún inexplorado, el conocimiento de las lenguas autóctonas, la catequesis de la población, la administración de los sacramentos. A estos quehaceres propios del apostolado se sumaron las tareas de recopilar información sobre la cultura otra y de dejar registro de la misma. Estos escritos comprenden historias, informes, solicitudes, crónicas, cartas, algunos producidos por solicitud de la Orden y otros por motivos que responden a cuestiones personales o a necesidades inherentes a la misión.

Dentro de este amplio corpus franciscano, dos textos en particular se ocupan, además del "pasado" de los pueblos originarios, de la evangelización novohispana y de su supuesto triunfo debido al servicio franciscano. Me refiero a las crónicas misioneras Historia de los indios de la Nueva España (1541) de Toribio de Benavente Motolinía ${ }^{1}$ e Historia eclesiástica indiana (ca. 1597) de Gerónimo de Mendieta. ${ }^{2}$ En estos textos el objetivo

\footnotetext{
${ }^{1}$ Toribio de Benavente Motolinía nació en 1490 (Baudot, 1983: 249) en Paredes, aldea situada a quince leguas de la villa de Benavente, en la provincia española de Zamora. Realizó sus votos hacia 1516 en Santiago. Con Martín de Valencia como cabeza de la misión, Motolinía y sus compañeros llegaron a México en junio de 1524 y fueron recibidos por Hernán Cortés. Motolinía fungió como primer guardián del monasterio de México. Fue Vicario Provincial de su Orden y ejerció las guardianías de Texcoco, Tlaxcala, Atlixco, Cholula. En 1558 fue castigado por su propia Orden con pena de un año de cárcel, denunciado por el arzobispo de México, el dominico Montúfar, quien recriminaba a Motolinía el tenor de las cartas que enviaba al rey. La prisión duró hasta 1560, luego de lo cual fue enviado a retiro hasta su muerte, en 1569. Fue el último de los Doce en morir. La Historia de los indios de la Nueva España es el resultado final de un conjunto de textos conocido como Memoriales, borradores de trabajo que sirvieron de apunte para la obra definitiva del fraile (Baudot, 1985: 53). La primera edición parcial fue realizada en 1848 por el anticuario irlandés Lord Edward Kingsborough. La edición completa más antigua corresponde al tomo I de la Colección de documentos para la historia de México (1858) de Joaquín García Icazbalceta. El original no ha sido hallado. Solo quedan tres copias manuscritas, ninguna ológrafa y con distintos títulos, en la colección privada de A. Ortiz Mena en la Ciudad de México, en la Biblioteca de El Escorial y en la Hispanic Society of America de Nueva York (Serna Arnaiz y Castany Prado, 2014: 89-90). La Historia de Motolinía se compone de tres partes (Serna Arnaiz y Castany Prado, 2014) o tratados I, II y III (Baudot, 1985) que comprenden quince, once y diecinueve capítulos, respectivamente. En este trabajo utilizo la edición preparada por Mercedes Serna Arnaiz y Bernat Castany Prado (Real Academia Española-Centro para la Edición de los Clásicos Españoles, 2014).

${ }^{2}$ Gerónimo de Mendieta nació en Vitoria, España, en 1525, y murió en México en
} 
primordial es mostrar la labor de la Orden de los Menores y señalar que, sin ella, la introducción del cristianismo hubiera sido inviable. Además, el enunciador subraya su lugar de pionero de la evangelización novohispana, locus que no se encuentra en las crónicas escritas por frailes de otras órdenes. Son textos en los que coexisten complejamente la descripción y la argumentación, la tradición indígena y la occidental, el relato etnográfico y el propagandístico de la Orden.

A pesar de las diferencias de tono y registro y del posicionamiento enunciativo levemente disímil entre una crónica y otra, observo en ambas un "modo del decir" la historia y la misión que las distingue del resto de los escritos de sus correligionarios. Los recursos implementados, los usos de la primera persona, las alusiones bíblicas, la organización de la información, entre otras cuestiones, hacen de estas crónicas textos que dicen distinto y, en esa modulación, dicen otra cosa. Si existe una "marca" o "método franciscano" en los escritos de la Orden de los Frailes Menores (Duverger, 1990), me interesa indagar en esta oportunidad en las características propias que hacen de las crónicas misioneras de Motolinía y Mendieta textos con un "modo del decir" atípico dentro de la cronística colonial.

1604. Tomó los hábitos posiblemente a los quince años, en Bilbao. En 1553 se alistó en la expedición misionera que reunía por entonces Francisco de Toral y llegó a México al año siguiente, treinta años después que los Doce primeros. Recién arribado, continuó y completó estudios de teología, aprendió náhuatl, comenzó su labor evangelizadora bajo las órdenes de Motolinía y escribió con profusión a Carlos V sobre la situación de los indígenas. Excepto por un breve lapso en que viajó a España (1570-1573), permaneció siempre en México. En 1571 el general de la orden franciscana, Cristóbal de Capitefontium, le ordenó regresar a México y elaborar una historia sobre la labor franciscana en Nueva España desde su llegada. Entre 1595 y 1596, retirado en el eremitorio de Huexotla, Mendieta ordenó los materiales recolectados e inició la redacción de la Historia eclesiástica indiana, que finalizó hacia 1597. Mandó hacer dos copias de su texto: una de ellas fue entregada a Juan de Torquemada para que quedase a resguardo en México y fue utilizada para la redacción de Monarquía indiana. La otra copia fue remitida a Cantabria, provincia franciscana de donde era originario Mendieta. La copia utilizada por Torquemada permanece extraviada. La segunda, en cambio, se encuentra en la Latin American Collection de la Universidad de Austin, Texas. El manuscrito contiene 336 fojas con letras distintas, obra de copistas conventuales, y contiene diez ilustraciones. Joaquín García Icazbalceta es quien halló este manuscrito entre los papeles de Bartolomé José Gallardo en Madrid y el responsable de costear su primera edición en 1870. Historia eclesiástica indiana se organiza en cinco libros divididos en capítulos. Para este artículo utilizo la edición preparada por Antonio Rubial García (Conaculta, 2002). 


\section{El locus misionero}

Misionero, caminante, catequista, lingüista, cronista. El fraile franciscano es un sujeto colonial (Adorno, 1988) multifacético y móvil que adopta diversas funciones dependiendo de las necesidades del apostolado. En sus incesantes actividades, reúne información proveniente de sujetos y culturas que repercute en crónicas atravesadas por discursos de distintas tradiciones.

Estos cruces se evidencian en los textos. A pesar de que los enunciadores de las crónicas misioneras de Motolinía y Mendieta excusan su desorganización y sus vacíos textuales mediante el topos humilitatis, sus Historias son textos organizados y pensados. Los relatos del pasado indígena, la evangelización novohispana y el presente "iluminado" por la fe se suceden estratégicamente con la intención de anunciar el acercamiento al otro y el "éxito" de la evangelización. Esta preponderancia de la profusión y reiteración no condice con la austeridad promulgada por las mismas crónicas. Si los franciscanos se presentan como los motolinea de sus propios textos, el enunciador de sus crónicas gesta un discurso incansable que repite anécdotas y hechos similares y que promulga los mismos valores una y otra vez. Sin embargo, y a pesar de esta voluntad de exceso, la omisión es otra de las características de las crónicas misioneras. Una omisión que es estratégica, pues, así como se elide el relato de la violencia de la conquista, también se elide el del trauma que sobrevino y el proceso de amoldamiento y adecuación al presente colonial, neutralizando los aspectos de la conquista que resultan inadecuados desde el ideal cristiano (Pastor, 1999: 193).

Bien mirada la historia, no se puede sino pensar el adoctrinamiento de indígenas como un acto por completo represor y opresor. No obstante, esto no aparece en la crónica misionera, que brinda escenas por lo menos sospechosas en las que los indígenas acuden solícitos y felices a las celebraciones sacramentales, escenas "naturales" de una "vida religiosa en el México colonial” (Rubial García y García Ayluardo, 1991) que brinda una engañosa sensación de homogeneidad. Es por esto que los "enemigos" a combatir en las crónicas misioneras son, al principio (esto es, en el relato del pasado indígena), Satanás y los ritos idolátricos y, una vez consumada la evangelización, los españoles “malos cristianos" que con su relajamiento de las costumbres hacen peligrar lo conseguido por los franciscanos. Estos 
españoles no son los conquistadores de las huestes cortesianas que han posibilitado la llegada del cristianismo, sino los encomenderos que pretenden beneficiarse de la servidumbre indígena y que también serán motivo de queja en las cartas individuales y colectivas franciscanas. A ellos se dirige la vehemencia crítica del enunciador en innumerables oportunidades.

Para construir este discurso entre crítico y entusiasta, las crónicas misioneras construyen un sujeto de la enunciación que de manera constante hace alusión a un "yo" que "vio" y "estuvo", sujeto experiencial que, en y desde Nueva España, es capaz de transmitir un mensaje esperanzador/ evangelizador avalado por su locus misionero y que, a la vez, se inscribe como apóstol que, luego de la muerte de Cristo, es el responsable de transmitir sus enseñanzas. Este enunciador se hace eco de las palabras apostólicas, "Lo que hemos visto y oído se lo anunciamos también a ustedes para que estén en comunión con nosotros" (1 Juan 1, 3), y de la voz de Pedro y Juan, "Nosotros no podemos dejar de hablar de lo que hemos visto y oído" (Hechos 4, 20). De esta manera, encontramos una insistente presencia del pronombre "yo" y de verbos de acción conjugados en una primera persona singular que resulta fundamental. ${ }^{3}$ Sin embargo, si el enunciador de la Historia de los indios de la Nueva España insiste en haber sido testigo, en haber visto, en tanto pionero de la evangelización, el de Historia eclesiástica indiana se muestra como un sujeto hiperactivo que observa, conversa, visita, ejerce cargos importantes y administra sacramentos, acorde al particular locus desde el que enuncia. A la vez, a causa de la modestia franciscana y a pesar de la constante alusión al yo, el fraile no utiliza su nombre para aludir a sí mismo. Y en caso de que el relato lo requiera, se refiere a sí mediante la tercera persona singular: "Diré cómo se ocupó un sacerdote

${ }^{3}$ Algunos de los ejemplos de Historia eclesiástica indiana son: "he visto" (2002, I: 125; III: 474), "saqué a los indios de esta regla general" (2002, I: 149), "fue mi guardián y lo traté y conocí por santo varón" (2002, III: 380), "yo muy bien conocí" (2002, III: 460), "yo la consolé y esforcé cuanto pude" (2002, IV: 123), "siendo yo guardián en la ciudad de Tepeaca" (2002, IV: 210), "yo que lo escribo y fui su súbdito". Sucede lo mismo en Historia de los indios de la Nueva España: "soy testigo" (2014: 11), "yo tengo carta" (2014: 14), "yo he visto y conocido" (2014: 32), "yo fui a ver" (2014: 49), "yo vi y supe" (2014: 108), "yo por mis propios ojos" (2014: 122), "yo soy buen testigo porque lo vi muchas veces" (2014: 266). Algunas de estas expresiones introducen una suerte de lectura crítica por parte del enunciador: "tengo para mí" (Mendieta, 2002, I: 124; IV: 22), "cada vez que me acuerdo y oigo semejantes agravios" (Mendieta, 2002, IV: 193), "yo no sé con qué fundamento" (Mendieta, 2002, IV: 81), "yo no tengo de juzgar esto" (Mendieta, 2002, IV: 87). 
que estando escribiendo esto, vinieron a llamar de un pueblo” (Motolinía, 2014: 135), "una carta que escribió un flaire morador de Tlaxcala a su provincial” (Motolinía, 2014: 88). De igual forma, el recurrente "nosotros" de las crónicas misioneras alude al fraile franciscano: "Los nuestros" (Mendieta, 2002, I: 134) son los religiosos de la Orden de San Francisco. ${ }^{4}$ Aun así, el "nosotros" de Motolinía se reduce a los franciscanos pioneros de Nueva España, mientras que en Historia eclesiástica indiana parece aludir a toda la orden, a aquellos que vinieron y a los que están por llegar. Esta primera persona tanto singular como plural se ve, por momentos, interrumpida por un discurso distanciado en tercera persona que, en su contraste, produce un efecto de cercanía y alejamiento muy particular. Los insistentes "decían” (Mendieta, 2002, II: 209), “dicen que” (Mendieta, 2002, II: 213, 268, 271; IV: 39), “tenían” (Mendieta, 2002, II: 225), "según algunos” (Mendieta, 2002, II: 293) se encuentran, preponderantemente, en las partes en que el enunciador describe el pasado indígena y pretende distanciarse de esas prácticas y dejar en claro que sólo las consigna sin avalar.

En estas crónicas existe lo que llamo un “discurso del lamento”, en relación no solamente con la labor escrituraria que debe realizar todo fraile sino, también, con el sufrimiento corporal, gajes del oficio del misionero franciscano. Es así como el enunciador de la crónica misionera se ocupa de especificar, con alto nivel de detallismo, las tareas del fraile y sus respectivas dolencias. Por ejemplo, alude al dolor de brazos que causa a los frailes sostener el jarro del bautismo durante horas ya que, si bien cambian el recipiente de brazo para evitar mayores daños, terminan doloridos de ambos por bautizar un solo día a seis mil personas (Mendieta, 2002, III: 422), a los callos y llagas en las manos por la manipulación de elementos bautismales y a las quemaduras del sol en la cabeza por estar fuera del convento al servicio de los indios (Motolinía, 2014: 174). Encontramos en estos textos muchos relatos que siguen una trama similar: a un fraile en un determi-

4 En Historia eclesiástica indiana estas alusiones son constantes: "nuestra madre" (2002, II: 196), "viniendo espantados a consolarse con nosotros" (2002, II: 206), "cosas de nuestra santa fe" (2002, III: 489), "nuestra orden" (2002, IV: 44), "los frailes de nuestra orden, nuestra compañía” (2002, IV: 113), "la orden de nuestro padre S. Francisco” (2002, V: 452). Lo mismo sucede en Historia de los indios de la Nueva España: "comenzamos a deprender la lengua y a predicar con intérprete" (2014: 154), "acurrieron a nuestro monasterio" (2014: 156). 
nado pueblo, le dolía la calva por la exposición solar; a otro fraile, en otro pueblo, le sangraban los pies por rehusarse a usar sandalias, dolores que, según Mendieta, sufrían, entre otros, Martín de Valencia (Mendieta, 2002, V: 292) y Diego de Olarte quien, mientras caminaba, iba "desangrando los pies" (Mendieta, 2002, V: 366). Recordemos que San Francisco, al recibir las llagas de la pasión de Cristo mediante una aparición divina (clavos en sus manos y pies, una herida sangrante en el costado derecho en el que Cristo recibió la lanza), rechaza todo tipo de medicina que pudiese aliviar el insoportable dolor, pues deseaba vivir con alegría dicho regalo (Montegiorgio, 1934: 149-150). De esta forma, los frailes se autorrepresentan como un nuevo Francisco: guerreros, misericordiosos, humildes, enfermos, agotados y con dolencias que emulan los estigmas de Cristo que sufrió el santo.

Si bien muchos historiadores han informado acerca del supuesto éxito rotundo de la evangelización en Nueva España, ${ }^{5}$ en crónicas como las de Motolinía y Mendieta puede observarse la oscilación ante dicha afirmación. El enunciador de Historia de los indios de la Nueva España se contradice permanentemente entre la existencia e inexistencia de prácticas idolátricas: su "hoy" se superpone y confunde con el "antes" novohispano y repercute en la enunciación. En Historia eclesiástica indiana, el enunciador describe un mundo idílico en el que multitudinarias masas acudían a las celebraciones sacramentales para, luego, indicar desazonadamente que dicho mundo está a punto de perderse a causa de los que deberían formar parte del "nosotros", esto es, los españoles. El enunciador de la crónica misionera, entonces, oscila entre la proclama de una contundente conversión y la realidad del presente colonial que lo refuta de manera constante. Entre la dicha por la labor lograda y la desesperanza por lo que se podría perder, es un yo entre la celebración y la advertencia, entre el asombro y la ruptura.

${ }^{5}$ Como afirma Pilar Gonzalbo Aizpuru: "Quizá por su excesiva confianza en la acción transformadora de la educación, muchos historiadores han minimizado la importancia de la resistencia pasiva opuesta por los indígenas a la penetración de las ideas y costumbres impuestas por los conquistadores. Los frailes evangelizadores incurrieron inicialmente en el mismo error y modificaron más tarde su apreciación, moderando su optimismo, al ver que los neófitos, en apariencia sumisos, seguían siendo 'idólatras en su corazón' mientras parecían cristianos en su exterior" (2001: 19). 


\section{Cruces discursivos}

En las crónicas misioneras encontramos elementos provenientes del conocimiento del náhuatl, como la incorporación de anécdotas muy dialogadas (como las "pláticas" o "exhortaciones" similares a los huehuetlatolli que incorpora el Libro II de Historia eclesiástica indiana), anáforas, ${ }^{6}$ parataxis $^{7}$ e iteración. ${ }^{8}$ Esto sucede por varios motivos: la preocupación de los frailes por adquirir la lengua autóctona con un fin evangelizador (Motolinía y Mendieta eran grandes "lenguas"), la recopilación de testimonios orales en náhuatl que el fraile interpreta y traduce para incorporar a su crónica o la misma labor evangelizadora que infunde cierta tonalidad nahua a los escritos misioneros. Lo cierto es que la inclusión de estos recursos no se relaciona con la dificultad de nombrar lo nuevo, sino con un remedo de la lengua autóctona que los frailes incorporan paulatinamente a la suya. La iteración se produce, en general, ante la descripción de prácticas de la cultura otra que el enunciador, de alguna manera, enjuicia, o de la que se distancia. La parataxis da cuenta de la profusión escrituraria a partir de esos muchos elementos de la cultura ajena y de una suerte de inconclusión

\footnotetext{
6 "Mayor milagro es haber traído a tanta multitud de idólatras al yugo de la fe cristiana, sin milagros, que con ellos. Mayor milagro es resucitar un alma muerta por el pecado y serle causa de eterna vida, que resucitar un muerto en el cuerpo, que tarde o temprano ha de tornar a morir. Mayor milagro es curar y sanar un vicioso, que un enfermo del cuerpo" (Mendieta, 2002, V: 260); "Allí pasaba él con mucho rigor sus ayunos y cuarentenas; allí ejercitaba deveras sus acostumbradas penitencias; allí se le pasaban días y noches en continua oración y meditación de la pasión de Cristo crucificado, mortificando su carne con diversos géneros de aflicción y castigo. Allí se cuenta que salía de la cueva a orar por las mañanas a una arboleda, y se ponía debajo de un árbol grande que allí estaba, y en poniéndose allí se henchía el árbol de aves que le hacían graciosa armonía" (Mendieta, 2002, V: 304).

${ }^{7}$ Algunos de los muchos ejemplos de parataxis son: "Y no querían entender en otra cosa sino en darse a vicios y pecados, dándose a sacrificios y fiestas, comiendo y bebiendo y embeodándose en ellas, y dando de comer a los ídolos de su propia sangre, la cual sacaban de sus propias orejas, lengua y brazos y de otras partes del cuerpo" (Motolinía, 2014: 26); "y allí en el agua echaban mucho incienso ofrecido y papel. Y cerca de los grandes árboles hacían lo mismo, y en los bosques. Y delante de los ídolos trabajaban mucho de plantar cipreses y unas palmas silvestres que se crían mucho hacia las tierras calientes. Los ídolos que tenían eran de piedra, y de palo, y de barro: otros hacían de masa y de semillas amasadas, y de éstos unos grandes, y otros mayores, y medianos, y pequeños y muy chiquitos" (Mendieta, 2002, II: 195).

8 "Errores y cegueras", "ritos y ceremonias", "desatinos y disparates" (Mendieta, 2002, I: 179), "culpas y pecados" (Mendieta, 2002, III: 441), "hongos o setas" (Motolinía, 2014: 27), "ídolos o dioses", "sacerdotes o papas", "pascua o Teuxituitl" (Mendieta, 2002, II: 217), "teocalme o templos del demonio", "papas o ministros" (Motolinía, 2014: 30).
} 
de la escritura, que es un rasgo de la crónica misionera. Pero, a su vez, se vincula estrechamente con la oralidad de la tradición indígena, gestando uno de los tantos cruces discursivos. También debido a esto, y en contraste con otras crónicas de tradición occidental, los enunciadores de estas Historias son quienes más atentos se muestran respecto del conocimiento de la etimología de los términos, preocupados por entender y hacer que otros entiendan la cultura. ${ }^{9}$ A la vez, dichas inclusiones funcionan como advertencia a los frailes que "pasarán a estas partes" sobre la importancia de involucrarse con esa nueva lengua para lograr un encuentro eficaz. La mayor atención a lo etimológico se halla en la parte en que se describen las prácticas seudo-sacramentales de los indígenas, como intento de comprensión de esas costumbres.

La profusión de gerundios puede ser leída, a su vez, como un rasgo de la cronística misionera: "todo lo henchían de pared, yendo echando sus lechos uno sobre otro, y subiendo la obra y base metiendo adentro" (Mendieta, 2002, II: 193); "Pero los tiempos andando y faltando gracia y doctrina, añadiendo los hombres pecados a pecados" (Mendieta, 2002, II: 197), "iban quemando y robando cuanto hallaban" (Mendieta, 2002, II: 251), "dándose a sacrificios y fiestas, comiendo y bebiendo y embeodándose en ellas, y dando de comer a los ídolos de su propia sangre” (Motolinía, 2014: 26); "salían de nuevo niños cantores cantando y bailando delante del Santísimo Sacramento" (Motolinía, 2014: 84). Estos y otros ejemplos dan cuenta de una voluntad de describir un transcurrir, un estado procesual y no finiquitado, un movimiento prolífico hacia la fe pero, además, resulta un remedo de la iteración típica del náhuatl que sobre un concepto desplaza uno o más términos equivalentes del mismo.

Las crónicas misioneras hacen uso de un discurso exaltado a través

9 "Y también le decían Moyucuyatzin ayac oquiyocux, que quiere decir 'que nadie lo crió o formó, sino que él solo por su autoridad y por su voluntad lo hace todo' (Mendieta, 2002, II: 196); "Los capellanes asimismo eran cuatro a los cuales llamaban Monauhxiuhzauhque, que quiere decir 'ayunadores de cuatro años'" (Mendieta, 2002, II: 220); "Llamaban a esta masa, Toyolliaytlaqual, que quiere decir: manjar de nuestra alma" (Mendieta, 2002, II: 225); "Y así decían: Aquin yeuitz, que quiere decir: ya viene alguno, o ċquién viene aquí?” (Mendieta, 2002, II: 226); “desembarcó con cuatrocientos españoles en el puerto de esta tierra firme, llamada entonces Anáhuac, que quiere decir ' cerca de las aguas o junto a ellas'" (Mendieta, 2002, III: 304); "y así le decían en su lengua, Totetzauh, que quiere decir 'nuestro prodigio'" (Mendieta, 2002, III: 471); "se deriva de michi, que quiere decir pescado" (Mendieta, 2002, IV: 34). 
de numerosas exclamaciones, ${ }^{10}$ preguntas retóricas ${ }^{11}$, hipérboles ${ }^{12} \mathrm{y}$, típico de la cronística occidental, el tópico de lo inefable que, en otras crónicas, como las mestizas, se asocia con la imposibilidad de escribir pero, en las misioneras, con diversos aspectos de la evangelización (o ausencia de la misma). Por ejemplo, en momentos en que se detallan los resultados adversos o favorables de la conversión, son comunes frases como: "Son tantos los inconvenientes que se han seguido y daños que se han recrecido con ellos, que no sé quién podría bastar a contarlos" (Mendieta, 2002, IV: 181), "Son tan grandes maravillas las que Nuestro Señor obra en ellos, que no las sabría decir, ni bastaría papel para las escrebir" (Mendieta, 2002, IV: 242-243).

El patetismo recorre toda la Historia eclesiástica indiana, fundamentalmente la segunda parte del Libro $\mathrm{V}$ que cuenta la vida de los "claros varones" mártires en el ejercicio de la misión. Por ejemplo, el relato sobre Andrés de Olmos, dice que "acaeció a este varón apostólico, que (permitiéndolo Dios para más mérito suyo) no le faltaron émulos y perseguidores, andando por los yermos desterrado, cansado y trabajado, evangelizando la palabra divina, todo comido de mosquitos, y por esto su rostro como el leproso llagado" (Mendieta, 2002, V: 357), o la anécdota que cuenta que Mo-

10 “iSea para siempre loado el Señor, que de tan excelente gobernador y piadoso príncipe y a tal tiempo nos proveyó!” (Mendieta, 2002, IV: 200-201); “iOh bienaventurados padres, siervos de Nuestro Señor, dechado de toda virtud, lumbreras que resplandecieron en el mundo como hachas encendidas en el amor de Nuestro Señor y del prójimo! iOh cómo les pareció que a ellos les fue mandado, después de los santos apóstoles, aquellos del Evangelio: 'Iréis por todo el mundo, y predicaréis el Evangelio a toda criatura'!" (Mendieta, 2002, V: 258).

11 “QQué otra cosa es baptizar, desposar, confesar, sino señalar siervos de Dios para que no sean heridos del ángel percuciente, y los así señalados trabajen de los defender y guardar de los enemigos que no los consuman y acaben?” (Motolinía, 2014: 176-177); “¿Pues qué es la causa porque a estos tales no se les dará el hábito de la religión, no solamente para legos, más aún para sacerdotes, como en la primitiva Iglesia se elegían los gentiles y judíos nuevamente convertidos a la fe para sacerdotes y obispos?" (Mendieta, 2002, IV: 118). El Capítulo XXXVII del Libro IV de Mendieta está repleto de preguntas retóricas que el enunciador coloca en boca del indígena, quien se queja de su situación desventajosa. Las preguntas retóricas son un remedo de los salmos bíblicos en su afán por hacer reflexionar al lector u oyente.

${ }^{12}$ Ejemplos concretos de hipérbole en las crónicas misioneras pueden ser el momento en que los indígenas cantan enfervorizados un "canto llano" cristiano que acaban de aprender (Motolinía, 2014: 34) o la recurrencia del enunciador de Historia eclesiástica indiana a confundir a los franciscanos (Martín Valencia o Francisco Lorenzo, por ejemplo) con "un ángel del cielo" (Mendieta, 2002, V: 265, 487). 
tolinía, ya enfermo, "fue cuasi arrastrando" a dar misa (Mendieta, 2002, V: 324). Pero el patetismo suele referir fundamentalmente a la devoción de los indígenas conversos. ${ }^{13}$

Por otro lado, en las crónicas misioneras son recurrentes las comparaciones con lo conocido. Motolinía utiliza a España como punto de comparación de aquello nuevo que observa: las sedas (2014: 10), los hongos comestibles (2014: 27), los "mercados o ferias" (2014: 41), las pelotas de juego (2014: 50), los animales (2014: 184, 198, 217), las sierras (2014: 188), las frutas (2014: 203), el licor (2014: 263), el calzado o "alpargates" (2014: 263). Todo en su crónica tiene punto de comparación con el universo occidental. Mendieta, por su parte, más preocupado por la situación del ocaso de la evangelización, se centra en la homologación de prácticas o costumbres relativas a la evangelización con la Biblia: David (2002, I: 107), Abraham (2002, I: 110), Job (2002, V: 407), Tobías, Judas (2002, V: 421), entre otros personajes bíblicos.

Si bien las crónicas misioneras presentan múltiples similitudes entre sí, también se distancian en algunos aspectos. Por ejemplo, el enunciador de la Historia eclesiástica indiana utiliza un registro más coloquial que el de Historia de los indios de la Nueva España: "no discrepa uno de otro una jota" (2002, II: 265), "Todos ellos son cortados por una tijera" (2002, III: 414), "apechugaron con ellos y tomáronlos en volandillas" (2002, III: 495), "me venía muy a pelo" (2002, IV: 246). Podemos pensar en que esta diferencia radica en los objetivos intrínsecos a las Historias de Motolinía y Mendieta. El primero, deseoso por describir el apogeo de la evangelización y de contagiar ese espíritu esperanzador en sus correligionarios, utiliza un registro, si bien exaltado, sencillo y directo. Mendieta, por su parte, construye un enunciador más enfático, vehemente e indignado, dado el contexto problemático al que he referido.

Por otro lado, detecto en el discurso de la Historia eclesiástica indiana una retórica salmódica también presente en crónicas mestizas como Historia de Tlaxcala de Diego Muñoz Camargo. Mendieta no solamente cita

13 "Acaecía por los caminos, montes y despoblados, seguir a los religiosos mil y dos mil indios y indias, sólo por confesarse, dejando desamparadas sus casas y haciendas; y muchas de ellas preñadas, y tanto que algunas parían por los caminos, y casi todas cargadas con sus hijos a cuestas" (Mendieta, 2002, III: 442). 
salmos bíblicos en varias oportunidades (2002, III: 392, 449; IV: 81) sino que, muchas veces, se hace eco de los mismos. Por ejemplo,

Nuestro omnipotentísimo Dios, cuyas obras son en sí maravillosas, siempre tuvo por estilo de engrandecer las cosas en el mundo humildes y pequeñas y abatir las altas. Y las misericordias y grandezas que por su infinita bondad ha querido mostrar a los hombres, siempre las obras por medio de instrumentos bajos y de poca estima cuanto al parecer del mundo. (Mendieta, 2002, III: 367) ) $^{14}$

Lo peculiar de este gesto es que también coloca la retórica salmódica cristiana en la voz del indígena:

Padre, no te enojes contra nosotros. Tú nos ayudaste andando desparramados y sueltos, y guiaste a los que andábamos descaminados, y como padre nos llevaste a la casa de Dios; ahora nosotros como hijos tuyos te llevamos a tu casa. Perdónanos, que no te querríamos dar enojo ni ofender, más que sacarnos los ojos. ¿Por ventura enojarse ha Dios con nosotros porque buscamos quien nos enseñe sus carreras y mandamientos? (Mendieta, 2002, III: 495) ${ }^{15}$

En este tipo de citas el fraile hace las veces de Dios-Padre que vela por sus hijos y los encamina. También de tonalidad salmódica son los muchísimos vocativos que incluyen las crónicas misioneras, también presentes en textos como el de fray Francisco de Osuna, Ley de amor santo (1530) o

14 "Los cielos cuentan la gloria del Señor, / proclama el firmamento / la obra de sus manos" (Salmo 19, 2); "iCuántas maravillas has hecho, Señor, mi Dios, cuántos proyectos a favor nuestro! Nadie se te puede comparar" (Salmo 40, 6); "Grande es el Señor, muy digno de alabanza, / y no puede medirse su grandeza. / De generación en generación / se celebran tus obras, se cuentan tus proezas. / El esplendor, la gloria de tu Nombre, / tus maravillas, los repetiré" (Salmo 145, 3-5); "Tú que habitas al amparo del Altísimo / y resides a la sombra del Omnipotente" (Salmo 90, 1).

15 "Señor, no me reprendas en tu ira, ni me castigues si estás enojado. Ten compasión de mí que estoy sin fuerzas; sáname pues no puedo sostenerme" (Salmo 6, 2-3); "Pero tú has visto la pena y el dolor, los miras y los recoges en tus manos. A ti el desamparado se encomienda, a ti que al huérfano socorres" (Salmo 10, 14); "los mandamientos del Señor son claros / y son luz para los ojos" (Salmo 19, 9); "No te alejes de mí, que la angustia está cerca, y no hay nadie que pueda ayudarme" (Salmo 22, 12); “¿Quién conoce la fuerza de tu cólera / y quién ha sondeado el fondo de tu furor? / Enséñanos lo que valen nuestros días, / para que adquiramos un corazón sensato. / Vuélvete, Señor, chasta cuándo? / Compadécete de tus servidores" (Salmo 90, 11-13). 
el Oratorio de fray Antonio de Guevara (1948): "amantísimo lector" (365), "lector ferviente" (228), "ioh digno lector!" (231), "amados hermanos" (490), "hermanos muy amados" (491), "hermanos míos" (503), "hermano" (585). Estos vocativos son recurrentes en el discurso misionero dado que son de uso constante en las homilías. Por momentos, el texto se estructura a la manera de un sermón: vocativo de tenor cristiano, pregunta retórica, alusión a alguna cita bíblica (generalmente, una parábola), explicación de la misma, punto de vista del enunciador sobre el tema relacionado a la realidad novohispana. Podemos pensar, entonces, que la crónica misionera por momentos adquiere el tono del sermón de misa: enseña (sobre los pueblos y costumbres), relata y describe escenas o parábolas (momentos de conversión, situaciones de idílica administración sacramental) y recomienda continuar el camino de la fe.

\section{"Pasar a estas partes". Reflexiones finales}

Con la profusamente utilizada metáfora "pasar a estas partes" el enunciador de las crónicas misioneras refiere a una suerte de camino de ida hacia la misión que le depara Nueva España, desafío que implica, además del involucramiento con paganos, el acercamiento a otras costumbres, lengua y cultura. En estos textos, el "pasaje" es solo de ida, un camino sin retorno que apenas un par de frailes traicionan al volver al viejo continente, agobiados por el peso de la tarea. ${ }^{16}$ Ante la importancia e insistencia del "pasar", el regreso a España es criticado como un acto grave de falta al deber. Por eso, el enunciador se esfuerza en indicar que, quien retorna, lo hace con el objetivo de gestionar recursos para mejorar la vida de los indígenas y, por supuesto, luego de eso, "pasar a estas partes" otra vez y definitivamente.

Este "pasaje" también es anuncio de un "modo del decir" distinto y distintivo que repercute en la escritura. Si la llegada a Nueva España es un camino sin vuelta atrás en cuanto a la experiencia (histórica, social, religio-

16 "Deseando pasar en estas partes para predicar" (Mendieta, 2002, III: 319), "pasar a estas partes" (Mendieta, III: 330; V: 331, 383), "los flaires de todas las órdenes que acá pasan" (Motolinía, 2014: 173), "pasando yo para estas partes en mi mocedad" (Mendieta, 2002, III: 330), "pasó a estas partes" (Mendieta, 2002, IV: 26; V: 447). 
sa), también lo es respecto de un modo de transmitir el registro de la historia, un "modo del decir" que, en contacto estrecho con los pueblos nuevos, cambia la forma de ver y (d)escribir el mundo.

De aquí que las crónicas misioneras, más allá de la "marca franciscana", adopten un discurso peculiar. La hipérbole, la exaltación, la tonalidad salmódica y proveniente del sermón, el énfasis en la descripción de escenas de conversión, el uso especial del "yo" que vio y fue testigo, entre otras, son sus características distintivas. Se asemejan a la retórica eclesiástica pero, a la vez, incluyen recursos provenientes de la cultura descripta. La escritura en estas crónicas se torna elemento que, como el sujeto, se descentra, reparte y comparte, y que manifiesta en sí la época tumultuosa, caótica, en ruinas y en permanente cambio.

Asimismo, en estas crónicas el discurso tiene, por momentos, cruces con la tradición indígena. Esto sucede no solamente porque los frailes acuden a fuentes prehispánicas y recogen testimonios orales que repercuten en su escritura sino, también, porque son grandes lingüistas y conocedores del náhuatl. Los gerundios, las reiteraciones, la parataxis, el patetismo e imágenes y metáforas típicas del universo nahua, entre otros recursos, muestran un discurso deudor de la tradición indígena. Si los franciscanos fueron los promulgadores de la importancia del acercamiento a las lenguas amerindias como primer paso para catequizar (conocer para enseñar), tanto en las incansables explicaciones etimológicas de términos nahuas (que no están presentes en otras crónicas de tradición occidental) como en la misma prosodia, se evidencia esa cultura ya, en parte, adquirida.

Por otro lado, Historia de los indios de la Nueva España e Historia eclesiástica indiana se encuentran estrechamente ligadas. Más allá de las diferencias tonales y de registro, una pareciera ser continuación de la otra: Mendieta retoma (lee, cita y reescribe) a Motolinía y redobla su apuesta (de conversión). Si una presenta la esperanzadora visión de la evangelización, la otra intuye con desazón la posibilidad de la pérdida de "almas". Estos posicionamientos estratégicos tienen por función postular a la Orden como el modelo ideal de misión. El contexto de Motolinía es, en apariencia, de ardua labor en tanto misión inicial. El enunciador de la Historia de los indios de la Nueva España se queja del escaso número de frailes en Nueva España, de lo mucho que hay para hacer y del poco tiempo que le queda a un fraile que debe, además, escribir. Por otro lado, Mendieta vive un momento 
más caótico, quizá, respecto de la disputa entre órdenes y miembros del clero. Escrita después del Concilio de Trento, Historia eclesiástica indiana adquiere, a lo largo del relato, un tono de advertencia ante el desgaste de la misión, desgaste propiciado tanto por los "malos cristianos" como por los dimes y diretes de y entre regulares, seculares y corte.

Esta labor escrituraria, continuada en el relato epistolar en ambos casos, se convierte en labor, más que informativa, propagandística, de la orden franciscana en Nueva España, y adopta un "modo del decir" atípico en su posicionamiento enunciativo y en su complejo cruce discursivo para convencer al lector de lo logrado en la evangelización y de la urgencia de seguir apoyando la causa de la Orden. Es la escritura, por tanto, parte inexcusable e imprescindible, mal que le pese al enunciador de la crónica misionera, de su tarea apostólica.

\section{Bibliografía}

Adorno, R. (1988). El sujeto colonial y la construcción cultural de la alteridad. Revista de crítica literaria latinoamericana XIV (28): 55-58.

Baudot, G. (1983). Utopía e historia en México. Los primeros cronistas de la civilización mexicana (1520-1569). Madrid: Espasa Calpe.

Baudot, G. (1985). Introducción biográfica y crítica. En Motolinía, T. de Benavente, Historia de los indios de la Nueva España (pp. 7-76). Madrid: Castalia.

Biblia Latinoamérica (1993). Madrid: Editorial San Pablo.

Duverger, C. (1990). La conversión de los indios de Nueva España. Con el texto de los Coloquios de los Doce de Bernardino de Sahagún (1564). Quito: Ediciones Abya-Yala.

Gonzalbo Aizpuru, P. (2001). Educación y colonización en la Nueva España, 1521-1821. México: Universidad Pedagógica Nacional.

Guevara, Fray A. de (1948). Oratorio de religiosos y ejercicio de virtuosos. En Gomis, J. B. (ed.), Místicos franciscanos españoles. Tomo II. Madrid: Biblioteca de Autores Cristianos.

Mendieta, G. de (2002). Historia Eclesiástica Indiana. México: Conaculta. Montegiorgio, H. (1934). Las florecillas de San Francisco. El cántico del sol. Madrid: Espasa Calpe. Recuperado de: http://www.cervantesvir- 
tual.com/obra-visor/las-florecillas-de-san-francisco-el-cantico-del-sol Motolinía, T. de Benavente (2014). Historia de los indios de la Nueva España. Madrid: Real Academia Española - Centro para la edición de los clásicos españoles.

Muñoz Camargo, D. (1998). Historia de Tlaxcala. Tlaxcala: Universidad Autónoma de Tlaxcala.

Osuna, Fray F. de (1948). Ley de amor santo. En Gomis, J. B. (ed.), Místicos franciscanos españoles. Tomo I. Madrid: Biblioteca de Autores Cristianos.

Pastor, B. (1999). El jardín y el peregrino. El pensamiento utópico en América Latina (1492-1695). México: Universidad Autónoma de México.

Rubial García, A. y García Ayluardo, C. (1991). La vida religiosa en el México colonial. Un acercamiento bibliográfico. México: Departamento de Historia de la Universidad Iberoamericana.

Serna Arnaiz, M. y Castany Prado, B. (2014). Introducción. En Motolinía, T. de Benavente, Historia de los indios de la Nueva España (pp. 9-104). Madrid: Real Academia Española - Centro para la edición de los clásicos españoles. 